\title{
INSTRUCTIVO PARA AUTORES
}

La Revista Inquietud Empresarial es una publicación científica semestral editada por la Escuela de Administración de Empresas de la Facultad de Ciencias Económicas y Administrativas de la Universidad Pedagógica y Tecnológica de Colombia, sede Tunja. Está dirigida a docentes universitarios, investigadores, empresarios, funcionarios públicos y privados, estudiantes de pre y posgrado como espacio de expresión del pensamiento de las Ciencias de la Administración, Económicas, Contables y Políticas.

Tiene por objeto divulgar avances y resultados de trabajos de investigación adelantados por docentes y estudiantes de la Escuela de Administración de Empresas y por los integrantes de los siguientes grupos de investigación, entre otros: "Competitividad y Desarrollo Local" - CODEL, "Investigadores para el desarrollo empresarial y agroindustrial sostenible" - IDEAS, "Proyectos organizacionales para el desarrollo empresarial de la región" - PODER, "Grupo de gerencia del valor y finanzas" - GEVA, "Laboratorio de Empresa” y "Observatorio Regional de Gestión Empresarial" - MIPYME.

Los artículos puestos en consideración del Comité Editorial de la Revista Inquietud Empresarial deben ser originales e inéditos y no pueden ser enviados simultáneamente a otro órgano de difusión; por consiguiente, aquellos textos que hayan sido publicados en otras revistas, no serán aceptados.

Los artículos deben ser presentados conforme a las técnicas de publicación establecidas por la revista. El proceso de evaluación en su primera etapa lo realiza el Editor quien seleccionará los manuscritos que cumplan con los criterios metodológicos y de contenido temático de la revista, si el material enviado cumple con esas normas, será sometido a la revisión y evaluación por parte de dos pares lectores especializados en el área temática respectiva; uno de ellos será interno y otro externo a la Universidad Pedagógica Tecnológica de Colombia. Diligenciada su evaluación, los pares lectores enviarán el dictamen a través del correo electrónico de la revista. El artículo evaluado podrá tener tres (3) resultados: publicable, publicable con ajustes, no publicable; cuando este se conceptúa como publicable con ajustes, se le informa al autor, quien decide si se compromete o no a realizarlos; si no los hace debe comunicar por escrito su decisión al Comité Editorial. El proceso de evaluación del artículo será de máximo tres (3) meses a partir de la fecha de recibo, y los jurados tendrán un plazo máximo de dos (2) meses calendario para conceptuar sobre la calidad del mismo. El Comité Editorial será quien finalmente decida la publicación o no de los artículos y el número de la edición en el que se incluirán. Es de aclarar que cuando surjan opiniones divergentes entre los dos lectores, el artículo se remitirá a un tercero, para dirimir la controversia.

Estas instrucciones, que contienen el proceso de dictaminación, serán conocidas previamente por el autor, a quien también se le advertirá, en forma escrita, que el proceso de evaluación de su artículo guardará estrictamente el anonimato; esto es, el autor no sabrá quién revisó su artículo, y el lector tampoco conocerá el nombre del autor (sistema doble ciego). De otro lado, para la autorización de derechos de autor, el Comité Editorial entrega un formato ("Autorización para publicación del artículo-copyright"-) al autor para que lo diligencie y se comprometa, mediante su firma, a ceder sus derechos a la revista.

Los interesados en enviar sus artículos deberán escribir al correo inquietud. empresarial@uptc.edu.co / revistainquietud.empresarial@gmail.com y seguir las instrucciones de formalización de datos, adjuntar el artículo y las figuras (si las 
contiene), y enviar la información en formato Word, no protegido. Es oportuno advertir que recibir un artículo no implica compromiso de la Revista Inquietud Empresarial para su publicación; esta será efectiva una vez emitidos los conceptos favorables por parte de los árbitros y el Comité Editorial.

El artículo aceptado con observaciones, según el criterio de los árbitros, será devuelto a su(s) autor(es) para que realice(n) las correcciones pertinentes. Una vez corregido, debe ser entregado al Comité Editorial en un tiempo no mayor a diez (15) días calendario. Si sobrepasa este plazo, se recibirá el trabajo, pero será publicado en un número posterior. El artículo no aceptado será devuelto al autor o autores con las observaciones correspondientes, y no podrá ser arbitrado nuevamente.

El Editor conserva facultades de la adecuación del artículo para la condición de requisitos, informando al autor los cambios realizados. En caso de ser rechazado el artículo, el autor recibirá comunicación por parte del Editor, dando la respectiva justificación; sin embargo, los artículos rechazados podrán ser enviados a otro evaluador a solicitud del autor.

Los autores de los artículos publicados tienen derecho a recibir un ejemplar del número de edición correspondiente.

A continuación el Comité Editorial de la revista expone los requisitos y características que deben contener los artículos presentados para posible publicación donde se deberá dar cumplimiento a los siguientes parámetros:

\section{Tipología de artículos}

La Revista Inquietud Empresarial acepta artículos originales de tipos 1, 2 y 3 según lo establecido por Colciencias:

1) Artículo de investigación científica y tecnológica. Documento que presenta de manera detallada los resultados originales de proyectos de investigación terminados. El cuerpo del trabajo debe contener los siguientes apartados: introducción, metodología, resultados y conclusiones.

2) Artículo de reflexión. Documento que presenta resultados de investigación terminada desde una perspectiva analítica, interpretativa o crítica del autor, sobre un tema específico, recurriendo a fuentes originales.

3) Artículos de revisión. Documento resultado de una investigación terminada donde se analizan, sistematizan e integran los resultados de investigaciones publicadas o no publicadas, sobre un campo en ciencia o tecnología, con el fin de dar cuanta de los avances y las tendencias de desarrollo de las Ciencias Administrativas, Económicas, Contables y Políticas. Se caracteriza por presentar una cuidadosa revisión bibliográfica de por lo menos 50 referencias.

4) Editorial. Documento escrito por el editor, un miembro del comité editorial o un investigador invitado sobre orientaciones en el dominio temático de la revista. 


\section{Requisitos técnicos del artículo}

Los autores deberán seguir las siguientes instrucciones de estilo y presentación de las producciones:

1. La primera parte del artículo deberá contener:

- Título del artículo: de no más de 15 palabras evitando el uso de siglas, símbolos y abreviaturas

- $\quad$ Nombre(s) del (de los) autor(es), y correo(s) electrónico(s). En nota de pie de página, es indispensable incluir lo siguiente:

- $\quad$ Tipo de artículo

- Nombre del autor

- Breve CV (títulos académicos y país de origen de la institución de adscripción de cada autor)

- Nombre del grupo de investigación, si es el caso

- Filiación institucional del autor

- Origen de subvenciones y apoyos recibidos, si los hubiere

2. En la segunda parte aparecerá: resumen, palabras clave, abstract, key words. En el Resumen es necesario presentar los objetivos del artículo, un contenido breve y los resultados; la extensión será mínimo 100, máximo 200 palabras en español y en inglés. Las Palabras clave son selecciones léxicas o frases cortas que recogen semánticamente los temas o asuntos relevantes de la disertación, su número será entre 5 a 7 palabras.

3. De la tercera página en adelante, debe aparecer: introducción, cuerpo del trabajo (metodología, resultados), conclusiones y referencias bibliográficas.

Se recomienda una redacción con estilo, escrito en tercera persona, observar las reglas ortográficas generales y la tilde para las mayúsculas; las expresiones en otro idioma o voces extranjeras van en letra cursiva (p.e., ad honoren).Las transcripciones textuales de citas van entre comillas. El cuerpo del manuscrito debe cumplir de forma obligatoria con las secciones enunciadas para cada modalidad como se explica a continuación:

La extensión del artículo debe estar entre 15 y 30 páginas que irán en formato carta. La fuente y el tamaño de la letra serán: Arial 12, interlineado 1.5 y para las citas textuales con sangría de párrafo, Arial 10, interlineado 1.0 y con márgenes en todo lado de $3 \mathrm{~cm}$.

Todos los párrafos tendrán una sangría de cinco espacios; es necesario dejar un espacio en blanco entre uno y otro, y entre las diferentes secciones del artículo. Los títulos y subtítulos estarán registrados con números arábigos. Las cursivas se usarán para escribir palabras de una lengua extranjera.

Las notas de pie de página deberán aparecer en números arábigos; se emplearán únicamente para aclarar, explicar o ampliar conceptos o datos que el autor considere que deben ir por fuera del texto. Los pie de página de símbolo $\left({ }^{*}\right)$ se utilizarán para consignar el tipo de artículo, el CV breve del autor, país de origen y el grupo de 
investigación al que pertenece.

Tablas, cuadros, gráficas y figuras, se citan dentro del texto con numeración consecutiva para cada tipo, especificar el título y la fuente de elaboración siguiendo el estándar de la citación en APA $6^{\mathrm{a}}$ versión (American Psychological Association). En caso de ser elaboración propia de los autores, se sigue la misma regla. Es responsabilidad del autor conseguir y entregar a la revista el permiso para la publicación de figuras que lo requieren.

Orden del manuscrito. 1. Cabeza del documento: título, resumen y palabras claves en el idioma original y con traducción en inglés o español según sea el caso; 2. Cuerpo del texto; 3. Tablas, cuadros, gráficas y figuras van al final con su respectiva citación dentro del texto; 4. Anexos; 5. Bibliografía o lista de referencias en orden alfabético.

Documentos adjuntos. 1. Carta de certificación de originalidad y cesión de derechos de autor; 2. Formato de autores; 3. Formato datos del artículo.

\section{Referencias bibliográficas}

La norma de estilo que establece la revista para citar y referenciar bibliografía toma en cuenta algunos aspectos de las técnicas APA actualizadas (sexta edición). Las referencias deben ser listadas, en orden alfabético, al final del documento. Para las referencias bibliográficas de revistas y/o libros, debe incluirse, en su orden: apellidos y nombres del autor, año de publicación, título del artículo (en letra redonda), lugar de publicación (seguido de dos puntos), nombre de la revista y/o libro en letra cursiva (volumen y páginas para el caso de las revistas); por ejemplo:

\section{Para artículos}

Alhama, R. (2006). "Organizaciones en aprendizaje y gestión del conocimiento". Revista sobre complejidad. Vol. 2, No 3.

Para libros

Pyzdek, T. y Berger, R. (1996). "Manual de control de calidad en la ingeniería”. McGraw Hill.

\section{Para fuentes tomadas de internet}

Debe incluirse, en su orden: título o descripción del documento. Fecha (puede ser la de publicación, actualización o de su recuperación). Dirección (URL "uniform resource locator"). Si es posible, se debe identificar a los autores; por ejemplo:

Armistead, C. (1999). "Knowledge Management and Process Performance". Journal of Knowledge Management. Vol. 3, No. 2. pp. 143-154. Recuperado 23/06/2013 de: http://www.bases.unal.edu.co:2104/journals. htm $?$ issn $=13673270 \&$ volume $=3 \&$ issue $=2 \&$ articleid $=883677$

Es importante que todas las referencias citadas en el cuerpo del texto guarden correspondencia con la bibliografía. No es conveniente insertar en las "Referencias bibliográficas" fuentes que no fueron citadas. El comité editorial de la revista recomienda incluir en las "Referencias bibliográficas" varias fuentes actuales. 


\section{Citas bibliográficas}

No se utilizarán las cursivas para las citas textuales. No obstante, cuando figuren en una cita deberá indicarse si el énfasis pertenece al original o al autor.

Las citas textuales de menos de 40 palabras deben incorporarse dentro del texto y encerrarse entre comillas inglesas. En el texto, solo se registra el apellido del autor, la fecha de publicación del libro y/o revista y el número de la página. Veamos un ejemplo de cada una de las distintas maneras de citar:

Carvajal y Zapata (2012) afirman que "Los individuos suelen ver lo que esperan ver y percibir de los productos y sus atributos de acuerdo con sus propias expectativas." (p. 112).

[...] "Los individuos suelen ver lo que esperan ver y percibir de los productos y sus atributos de acuerdo con sus propias expectativas." [...] Carvajal y Zapata (2012, p. 112).

Carvajal y Zapata (2012, p. 112) afirman que" Los individuos suelen ver lo que esperan ver y percibir de los productos y sus atributos de acuerdo con sus propias expectativas.". Al respecto...

Las citas textuales de 40 o más palabras se ubican en una nueva línea o renglón, en un bloque independiente, en la misma posición como un nuevo párrafo (cinco espacios desde el margen izquierdo en todos los renglones de la cita), según se señaló ya, en fuente Arial 10, interlineado 1.0 y sin comillas. Ejemplo:

También se observa en algunas ocasiones, por parte de los consumidores, la falta de claridad sobre las razones por las cuales no les resulta conveniente ingerir bebidas alcohólicas. Esto se sustenta, por ejemplo, en que recientemente se han hecho campañas que han buscado prevenir el consumo de alcohol, resaltando situaciones dramáticas o trágicas como accidentes de tránsito, muertes, entre otras; es decir, se hace con el propósito de que los consumidores de bebidas alcohólicas incrementen su nivel de conciencia sobre los efectos negativos que puede legar a ocasionar dicha práctica. (Carvajal y Zapata, 2012, p. 122)

De esta forma, Carvajal y Zapata (2012, p. 122) plantean que:

También se observa en algunas ocasiones, por parte de los consumidores, la falta de claridad sobre las razones por las cuales no les resulta conveniente ingerir bebidas alcohólicas. Esto se sustenta, por ejemplo, en que recientemente se han hecho campañas que han buscado prevenir el consumo de alcohol, resaltando situaciones dramáticas o trágicas como accidentes de tránsito, muertes, entre otras; es decir, se hace con el propósito de que los consumidores de bebidas alcohólicas incrementen su nivel de conciencia sobre los efectos negativos que puede legar a ocasionar dicha práctica.

En el caso de existir dos o más publicaciones del mismo autor en un mismo año, se debe agregar letras minúsculas a la fecha de publicación; por ejemplo, Stiglitz (2007a), Stiglitz (2007b).

Finalmente, se aclara que las anteriores pautas de estilo permiten uniformidad y estética en la presentación de la revista. Además, constituyen un parámetro de evaluación del artículo. 